\title{
Patient Monitoring using Internet of Things
}

\author{
Atul V Shah ${ }^{1}$ \\ Assistant Professor, Dept.of Electronics Engg. \\ DKTE's Textile \& Engg Institute, \\ Ichalkaranji, India
}

\author{
Prajakta $\mathrm{P}$ Bhandari ${ }^{2}$ \\ UG Student, Dept.of ElectronicsEngg. \\ DKTE's Textile \& Engg Institute, \\ Ichalkaranji, India
}

\begin{abstract}
Nowadays IoT is playing an important role in health care systems, which is not only helpful for monitoring the health parameters but also helpful for communicating, storing and displaying the monitored data. The main aim of the project is to design and implement effective health care patient monitoring system. The proposed system monitors the health parameters like Temperature, BP and Pulse rate etc. and then transmits the parameters wirelessly through wifi module technology. The transmitted data is displayed on the PC .This data gets updated into database continuously.From the database with the help of android application fetches all the updated data and displays it on doctor side personal mobile.This tells the doctor the current status of the patient in real time.If any parameter of a particular patient goes beyond a pre-assigned threshold value, then an automatic notification will send on doctors mobile using android mobile application. The system basically consists of hardware like sensors, microcontroller (ATmega16), LCD display,wifi module(ESP8266),MQTT protocol for sending data on cloud, android app etc.
\end{abstract}

\section{INTRODUCTION}

Internet of things (IoT) dependant patient monitoring is a network implemented to operate different medical sensors connected to the human body. Implementing it in medical application gives flexibility of operation. They reduce user discomfort and enhance mobility. Applications in this category include monitoring of the biological parameters, tracking and monitoring of the patients inside hospital. Applications in this category include monitoring of the biological parameters, tracking and monitoring of the patients inside hospital. Proposed system is a special purpose network designed to operate various medical sensors connected to the human body. They measures body's basic functions which can be helpful for monitoring general health of a person. The aim of the healthcare application is to provide better healthcare to all the people anywhere and at any time and purpose of the system is to prevent delays in the arrival of patient's medical information to the healthcare providers, especially in accident and emergency cases.

Basically the flow of system is based on medical sensors that measure patient's physical parameters with the help of wireless sensor networks (WSNs). These sensors transfer data from patient's bodies over the wireless network to the cloud environment. Cloud environment gives suitable and on-demand network access for number

of computing resources such as networks, systems, applications, and services. The proposed system consists of following component:

Sensing node: Each sensor node is connected with a microcontroller and a power source. The sensors will require limited source of energy. The sensing nodes will sense physical data then the monitor all conditions and performing small processing operations it will transmit data to other sensing nodes in network.

Transmission technology: Transmit data over network through Wi-Fi module with the help of Message Queuing Telemetry Transport (MQTT) protocol.

\section{SYSTEM DESCRIPTION}

\subsection{System Block diagram}

The block diagram of patient monitoring system is shown in figure. Here three IoT biomedical sensors named as temperature sensors, blood pressure sensors and pulse rate sensors are connected to AVR controller. They will sense medical parameters with respect to the three sensor then with the help of MQTT (Message Que Telemetric Transfer) publish-subscribe protocol the information of the patient is sent on cloud through wi-fi module and using

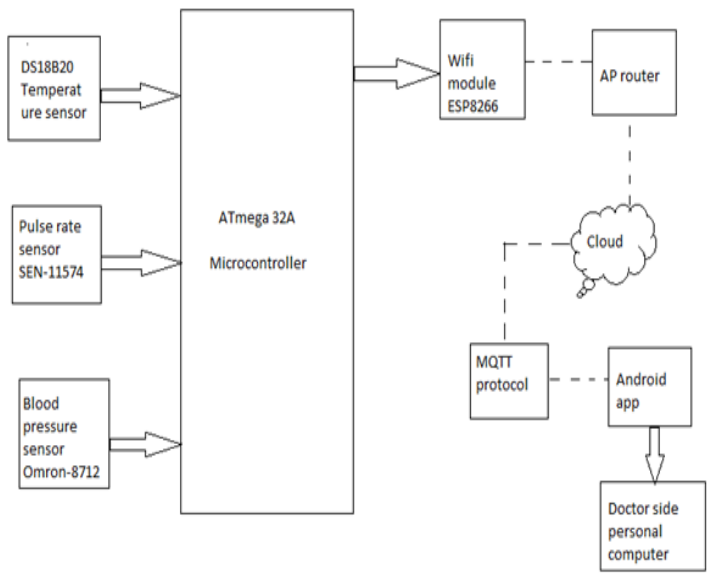

Fig. 1 Block diagram of patient monitoring system

\subsection{Methodology of Implementation}

In proposed system, three applications have implemented. These are as follows:
a. Data collection
b. Data on cloud
c. Decision making process

\section{a. Data collection}

Patient's physical parameters are measured using medical sensors that are connected to a microcontroller. It is responsible for collecting data from the sensors and transferring it over router, to the cloud environment. 
The sensors transmit real time data in the cloud continuously based on the set conditions which are in their configuration program.

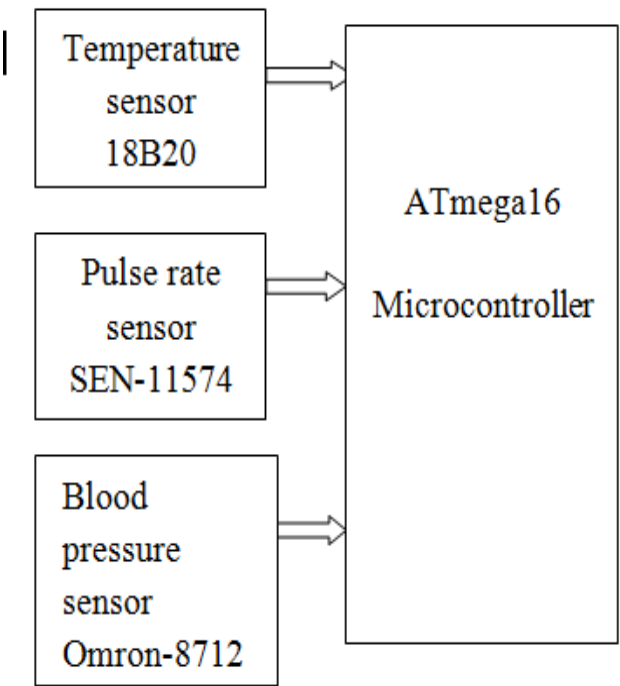

Fig. 2 Block diagram of data collection

The DS18B20 digital thermometer gives 9-bit to 12 bit Celsius temperature measurements. The DS18B20 communicates over a 1 -Wire bus requires only one data line (and ground) for communication with a central microprocessor. In addition, the DS18B20 can take power directly from the data line; it does not require external power supply.

Table 1Classification of temperature

\begin{tabular}{llll}
\hline Hypothermia & Normal & Fever & Hyperthermia \\
& & & \\
\hline$<35.0^{\circ} \mathrm{C}$ & $36.5-37.5^{\circ} \mathrm{C}$ & $>37.5$ or $38.3^{\circ} \mathrm{C}$ & $>40.0$ or $41.0^{\circ} \mathrm{C}$ \\
$\left(95.0^{\circ} \mathrm{F}\right)$ & $\left(97.7-99.5^{\circ} \mathrm{F}\right)$ & $\left(99.5\right.$ or $\left.100.9^{\circ} \mathrm{F}\right)$ & $\left(104.0\right.$ or $\left.105.8^{\circ} \mathrm{F}\right)$
\end{tabular}

Pulse Sensor is plug-and-play heart-rate sensor for controller. The sensor clips onto a fingertip and plugs right into microcontroller. The power supply voltage: $3.3 \mathrm{~V} \sim 5$

Table 2Pulse rate range

\begin{tabular}{lllll}
\hline $1-12$ month & $1-2$ years & $3-6$ years & $7-12$ years & Adolescence \\
\hline $120 \mathrm{bpm}$ & $110 \mathrm{bpm}$ & $100 \mathrm{bpm}$ & $95 \mathrm{bpm}$ & $80 \mathrm{bpm}$
\end{tabular}

Blood pressure is the pressure of the blood in the arteries as it is pumped around the body by the heart. When your heart contracts and pushes blood through the arteries to the rest of your body force creates pressure on the arteries. Blood pressure recorded as two numbers - the systolic pressure (as the heart beats) over the diastolic pressure (as the heart relaxes between beats).
Table 3Blood pressure range

\begin{tabular}{lll}
\hline AGE & GENDER & MIN/MAX(mmhg) \\
\hline$<18$ & Male & $80 / 120$ \\
18 to 20 & Male & $82 / 125$ \\
21 to 40 & Male & $85 / 135$ \\
40 and above & Male & $85 / 130$ \\
$<20$ & Female & $80 / 123$ \\
21 to 40 & Female & $82 / 133$ \\
40 and above & Female & $85 / 133$
\end{tabular}

b. Data on cloud

Here MQTT protocol suit is used. It is a publish subscribe type. MQTT broker will act as mediator between publisher and subscriber. The publisher will send or transfer the information regardless specific receiver. Receivers are categorized and receive information according to topic.

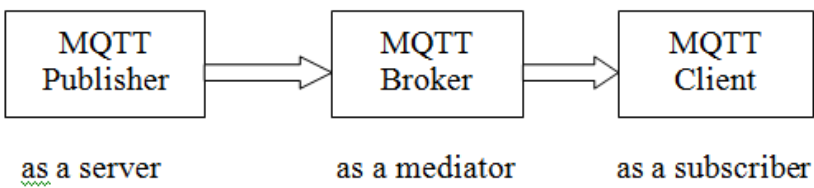

Fig. 3 Block diagram of MQTT basic architecture

The MQTT messages are delivered asynchronously ("push") through publish subscribe architecture. The protocol works with the help of exchanging a series of MQTT control packets where each one has a specific purpose and every bit in the packet is used to reduce the data transmitted over the network. Client and server communicate over different control packets. Steps to connect MQTT server are as follows:

Step 1: Download an application named "MQTT dashboard" on android Phone.

Step 2: Open application and Go to settings.

a. In First text box enter Client ID

b. In Second text box enter URL of MQTT server/client that is iot.eclipse.org

c. Third Text box is for Port, type 1883

d. Left username and password blank.

e. Press Create.

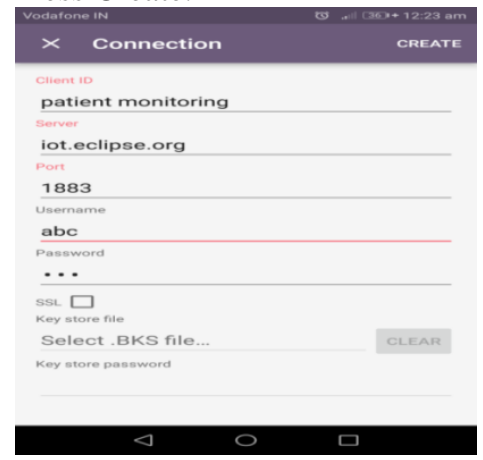

Fig. 4 MQTT server connection 
Step 3: Now you have to create a TOPIC in Phone

Step 4: To subscribe to the topic on Phone, you have to type the topic name in phone, which is "patient1".

In such manner connection with MQTT server is completed. For sending the data on cloud along with MQTT protocol we have used wi-fi module ESP8266.

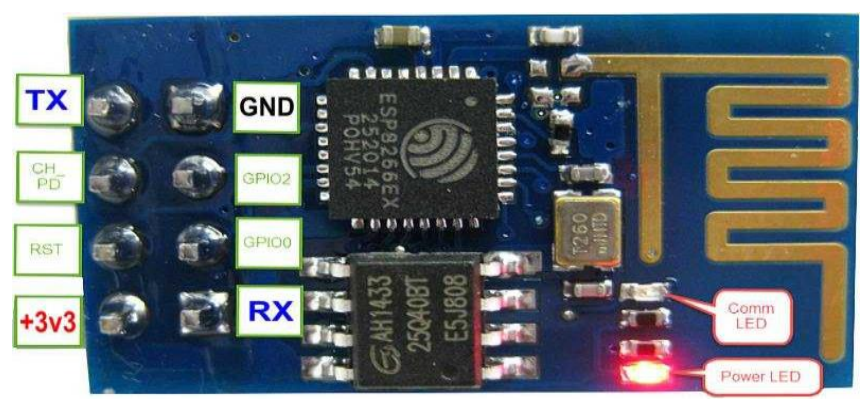

Fig. 4 wi-fi module ESP8266

The ESP8266 is low-cost Wi-Fi microchip with full TCP/IP stack and microcontroller capability. This small module allows microcontrollers to connect to a Wi-Fi network and make simple TCP/IP connections.

Basic flow chart:

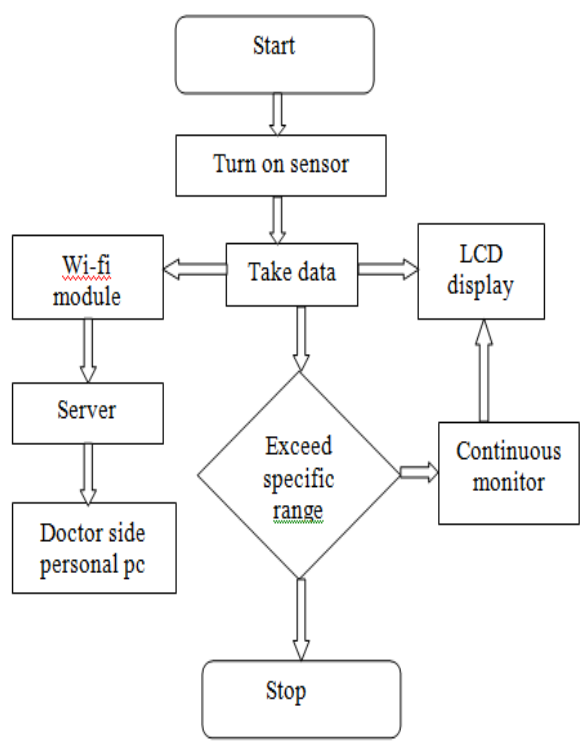

Fig. 5 flow of working process

d. Decision making process

Here sensor will sense the data that is human body's medical parameters such as temperature, pulse rate and blood pressure. If the data is normal then it is saved in database and it will send decision to doctors follow up Now if the is not normal then it will check medical condition the result is send for doctors approval for further treatment .

\section{DECISION APPROVAL}

After the system makes the decisions, it will be sent to medical staffs for the patient's healthcare for approval. There are different ways to notify medical staff including SMS \& email. They can use a web browser from any device to review and update decisions as needed. medical staff can decide if the current decision which are created from the system are right for the patient's condition or they need to change and update the them

\section{EXPERIMENTS}

This section describes results for patient monitoring system using IoT and then experiments which we have performed for performance calculation of implemented system. .

\subsection{Results}

Following figure shows that the results on LCD and android app. In the result following parameters are shown: Temperature, motion and position of animal.

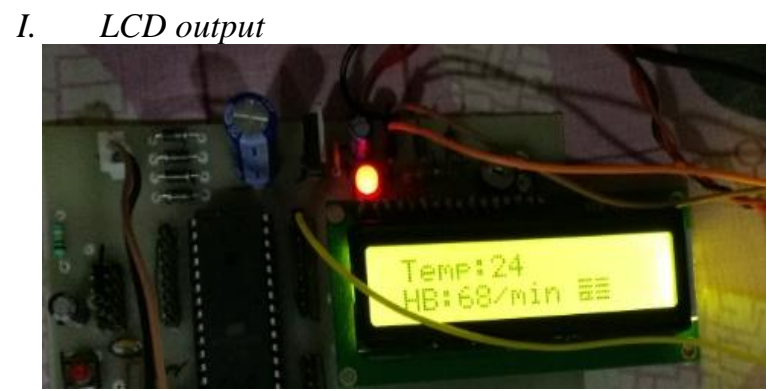

Fig. 6 output on LCD display

II. Temperature output

Table4 observation of temperature parameter

\begin{tabular}{|c|c|c|c|}
\hline Patient ID & $\begin{array}{l}\text { Temperature in }{ }^{\circ} \text { Cwhen } \\
\text { thermometer is connected } \\
\text { to hardware(measured } \\
\text { value) }\end{array}$ & $\begin{array}{c}\text { Temperature in }{ }^{\circ} \mathrm{C} \\
\text { Directly measured value } \\
\text { (expected value) }\end{array}$ & $\begin{array}{l}\text { Status of the patient with } \\
\text { respect to standard } \\
\text { temperature range }\end{array}$ \\
\hline Patient1 & 35.25 & 34.98 & Nomal \\
\hline Patient2 & 34.50 & 34.21 & Normal \\
\hline Patient3 & 36.50 & 35.88 & Normal \\
\hline Patient4 & 35.13 & 34.70 & Normal \\
\hline Patient 5 & 36.25 & 35.75 & Nomal \\
\hline $\begin{array}{l}\text { Patuents } \\
\text { Patient6 }\end{array}$ & 36.19 & 36 & Nomal \\
\hline $\begin{array}{l}\text { Patuento } \\
\text { Patient7 }\end{array}$ & 34.75 & 34.35 & Normal \\
\hline & 36.83 & 36.12 & Normal \\
\hline Patient8 & 36 & 35 & Normal \\
\hline Patient9 & 36 & 35 & Normal \\
\hline Patient10 & 36.12 & 35.13 & Normal \\
\hline Patient11 & & & Abnomal \\
\hline Patient12 & 36.61 & 35.66 & Normal \\
\hline Patient13 & 38.9 & 37 & Abnomal \\
\hline Patient14 & 36.98 & 36 & $\begin{array}{l}\text { Nomal } \\
\text { Ahmom }\end{array}$ \\
\hline Patient15 & $\begin{array}{l}40 \\
3833\end{array}$ & $\begin{array}{l}33.88 \\
3722\end{array}$ & $\begin{array}{c}\text { Abnomal } \\
\text { Normal }\end{array}$ \\
\hline
\end{tabular}

III. Pulse rate output

Table 5 observation of pulse rate parameter

\begin{tabular}{|c|c|c|c|c|}
\hline Patient ID & Age & $\begin{array}{c}\text { Pulse rate in } \\
\text { bpm When } \\
\text { sensor is connected } \\
\text { to hardware } \\
\text { (measured value) }\end{array}$ & $\begin{array}{c}\text { Pulse rate in } \\
\text { bpm Directly } \\
\text { measured value } \\
\text { (expected value) }\end{array}$ & $\begin{array}{l}\text { Status of the patient with } \\
\text { respect to standard pulse } \\
\text { rate range }\end{array}$ \\
\hline Patient1 & 52 & 68 & 60 & Normal \\
\hline Patient2 & 48 & 78 & 69 & Normal \\
\hline Patient3 & 55 & 70 & 62 & Nomal \\
\hline Patient4 & 50 & 75 & 68 & Nomal \\
\hline Patient5 & 42 & 65 & 60 & Nomal \\
\hline Patient6 & & 63 & 58 & Nomal \\
\hline & 40 & 60 & 69 & Nomal \\
\hline Patient? & 35 & 78 & 64 & Normal \\
\hline Patient8 & 32 & 73 & 62 & Nomal \\
\hline Patient9 & 48 & 71 & 62 & Nomal \\
\hline Patient10 & 55 & 70 & 62 & Normal \\
\hline Patient11 & 60 & 72 & 68 & Nomal \\
\hline Patient12 & 61 & 80 & 74 & Nomal \\
\hline Patient13 & & 77 & 69 & Normal \\
\hline $\begin{array}{l}\text { Pattent15 } \\
\text { Patient14 }\end{array}$ & 31 & 80 & 67 & Nomal \\
\hline Patient14 & 54 & 77 & 68 & Nomal \\
\hline Patient15 & 58 & 74 & 67 & Nomal \\
\hline
\end{tabular}




\section{Blood pressure output}

Table 6 observation of pulse rate parameter

\begin{tabular}{|c|c|c|c|}
\hline Patient ID & $\begin{array}{l}\text { Blood pressure in } \\
\text { mmhg When } \\
\text { cornected } \\
\text { to hardware } \\
\text { (measured value) } \\
\text { MaxMin } \\
\end{array}$ & $\begin{array}{l}\text { Blood pressurue in myhbg } \\
\text { Directly } \\
\text { mes sured value } \\
\text { (expected value) } \\
\text { Max Min }\end{array}$ & $\begin{array}{l}\text { Status of the } \\
\text { patient with } \\
\text { respect to } \\
\text { standard blood } \\
\text { pressur rang }\end{array}$ \\
\hline Patient1 & 12070 & $100 / 60$ & Normal \\
\hline Patient2 2 & 170100 & 160090 & Abnomal \\
\hline Patient3 & 13870 & 120160 & Nomal \\
\hline Patient4 & $180 / 110$ & $170 / 100$ & Altnomal \\
\hline 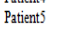 & $125 / 80$ & $120 / 70$ & $\begin{array}{l}\text { Nommal } \\
\text { Nomal }\end{array}$ \\
\hline Patient6 & 130180 & $110 / 70$ & Nomal \\
\hline Patient? & 13288 & 120.80 & Nomal \\
\hline Patients & 12982 & 120770 & Nomal \\
\hline Patient? & $\begin{array}{l}11080 \\
11080\end{array}$ & $\begin{array}{l}100 / 70 \\
\text { S }\end{array}$ & Nomal \\
\hline Patient10 & 12072 & $110 / 70$ & Nomal \\
\hline Patient11 & 200150 & $190 / 140$ & Atnomamal \\
\hline Patient12 & 12070 & $110 / 60$ & Nommal \\
\hline Patient13 & 11070 & 100770 & Nomal \\
\hline Paternt14 & 12080 & $110 / 70$ & Nomal \\
\hline Patertl15 & $\begin{array}{l}140880 \\
140\end{array}$ & $\begin{array}{l}130 / 70 \\
130\end{array}$ & Nomal \\
\hline
\end{tabular}

Above Table 4-6 shows humans basic body parameters that are the temperature, pulse rate and blood pressure parameter with different conditions.

\section{Android app output}

Fig.7 (a) and (7) shows the output on android app. It shows the temperature, pulse rate and blood pressure.

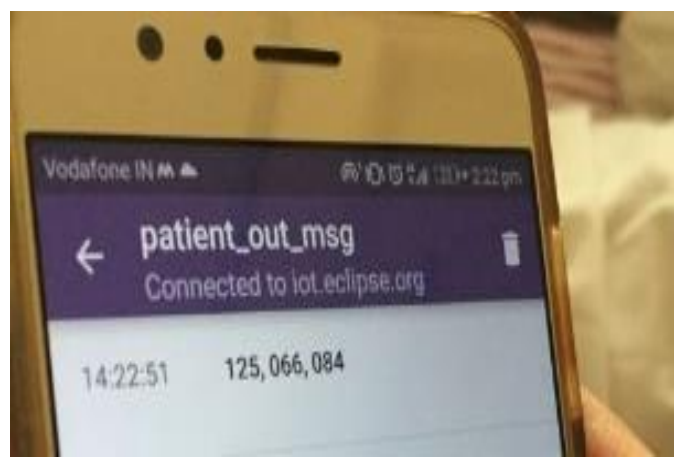

Fig.7 (a) Android app output

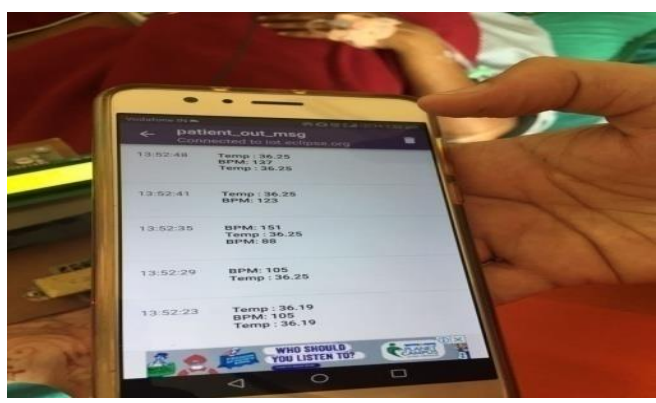

Fig.7 (b) Android app output

II. Performance parameter

1) Percentage error measure:

To calculate the performance of the system, we have to use a percentage error measure. It is the difference between a measured value and an expected value. The formula for percentage error is as follows:

$\%$ error $=($ approximate value - exact value $) \times 100 \%$
From above three table values \% error of temperature sensor calculated as:

- $\quad$ For reading no.1

$\%$ error for Temperature

Sensor $=($ measured value - expected value $) \times 100 \%$

$$
\begin{aligned}
& =(35.25-34.98) \times 100 \% \\
& =0.27 \times 100 \% \\
& =27 \%
\end{aligned}
$$

- $\quad$ For reading no.2

$\%$ error for Temperature

Sensor $=($ measured value - expected value $) \times 100 \%$

$$
\begin{aligned}
& =(34.50-34.21) \times 100 \% \\
& =0.29 \times 100 \% \\
& =29 \%
\end{aligned}
$$

Similarly we can calculate \% error of Pulse rate sensor and Blood pressure sensor

2) Accuracy:

Accuracy measures the ability of designed system to detect the true value or expected value with respect to the given condition. The formula for calculating accuracy is as follows:

$\%$ Accuracy $=(100 \%$ accurate system $-\%$ error measure $)$

From above three table values \% Accuracy of temperature sensor calculated as:

- For reading no. 1

$\%$ Accuracy $=(100 \%$ accurate system-\%error measure $)$

$$
\begin{aligned}
& =(100 \%-27 \%) \\
& =73 \%
\end{aligned}
$$

- $\quad$ For reading no. 2

$$
\begin{aligned}
\% \text { Accuracy } & =(100 \% \text { accurate system }-\% \text { error measure }) \\
& =(100 \%-29 \%) \\
& =71 \%
\end{aligned}
$$

\section{CONCLUSION}

In this paper we proposed a framework for patient monitoring using Internet of Things which used to transmit the data which is sensed from biomedical sensor to the server by using wi-fi module. It is completely integrated so that it is possible to measure human body's basic parameter anytime from anywhere. It has real time capability. The accuracy of system is affected by some factors such as time delay, network around the mobile, GPS receiver having accuracy is $93.33 \%$ and sensitivity of system is $93.33 \%$.

Circuitry is having less complexity and Modules used are smaller in size and also lightweight and portable. 


\section{REFERANCES}

[1] Vikas Vippalapalli,Snigdha Ananthula "Internet Of Things(IoT) based smart health care system" international conference on signal processing, communication and embedded system IEEE pp.1229$1233,2016$.

[2] Luca Catarinucci, Danilo de Donno, Luca Mainetti, Luca Palano, Luigi Patrono, Maria Laura Stefanizzi, and Luciano Tarricone. "An IoT Aware Architecture for Smart Healthcare Systems". IEEE JOURNAL, pp.515- 526, Dec 2015.

[3] Mohammad S. Jassas, Abdullah A. Qasem, Qusay H. Mahmoud "A Smart System Connecting e-Health Sensors and the Cloud". IEEE conference pp.712-716, May 2015.

[4] Tia Gao, Dan Greenspan, Matt Welsh, Radford R. Juang, and Alex Alm "Vital Signs Monitoring and Patient Tracking Over a Wireless Network"IEEE EMBS pp.102-105, 2005.

[5] Enrique Dorronzoro Zubiete, Luis Fernandez Luque Ana, Veronica Medina Rodriguez, Isabel Gomez Gonzalez . "Review Of Wireless Sensors Networks In Health Applications". IEEE Conference Sept 2011.

[6] S. M. Riazul Islam, Daehan Kwak, Md. Humaun Kabir, Mahmud Hossain, And Kyung-sup Kwak, "The Internet Of Things For Health Care: A Comprehensive Survey". IEEE Access, pp. 678-708, June 2015.

[7] Eric Campo and Etienne Grangereau "Wireless fall sensor with gps location for monitoring the elderly". Conf Proc IEEE Eng Med Biol Soc,pp.498-501, Jan 2008.

[8] Wan-Young Chung, Young-Dong Lee, and Sang-Joong Jung "A wireless sensor network compatible wearable u-healthcare monitoring system using integrated ecg, accelerometer and spo2". Conf Proc IEEE Eng Med Biol Soc, pp.1529-32, Jan 2008.

[9] Jong-Myoung Kim, Joo-Hyun Hong, Myeong-Chan Cho, EunJongCha, and Tae-Soo Lee "Wireless biomedical signal monitoring deviceon wheelchair using noncontact electro-mechanical film sensor". Conf Proc IEEE Eng Med Biol Soc, pp.574-7, Jan 2007.

[10] Daniel T H Lai, E Charry, R Begg, and M Palaniswami "A prototypewireless inertial-sensing device for measuring toe clearancev". Conf ProcIEEE Eng Med Biol Soc, pp.4899-902, Jan 2008.

[11] Rolim, C. O., Koch, F. L., Westphall, C. B., Werner, J., Fracalossi, A., \& Salvador, G. S. "A cloud computing solution for patient's data collection in health care institutions". In eHealth, Telemedicine, and Social Medicine, 2010. ETELEMED'10. Second International Conference IEE,pp. 95-99,Feb 2010.

[12] Lounis, A., Hadjidj, A., Bouabdallah, A., \& Challal, Y. Secure and scalable cloud-based architecture for e-health wireless sensornetworks. In Computer communications and networks (ICCCN), 21st international conference IEEE, pp. 1-7, July 2012.

[13] Michael R. Neuman, "Measurement of vital signs: Temperature", IEEE Pulse, Sept/Oct 2010. 